\title{
Synthetic Studies toward Parvistemoline Using Asymmetric Ir/Amine-Catalyzed Allylation
}

\author{
Yu Zheng, ${ }^{\dagger,}$ Hong-Dou Yang, ${ }^{\dagger, \dagger}$ Kun Wei, ${ }^{*, \dagger}$ and Yu-Rong Yang ${ }^{* \dagger}$ \\ ${ }^{\dagger}$ State Key Laboratory of Phytochemistry and Plant Resources in West China, Kunming Institute of \\ Botany, Chinese Academy of Sciences, Kunming 650201, China University of Chinese Academy of \\ Sciences, Beijing 100049, China
}

yangyurong@mail.kib.ac.cn; weikun@mail.kib.ac.cn

\section{Table of Contents}

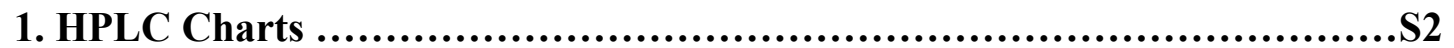

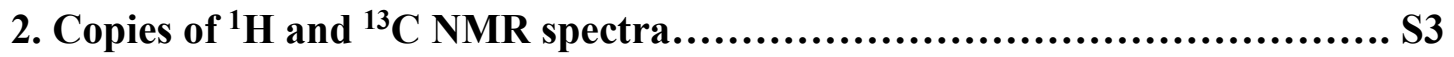

3. Parts of the HRMS analysis reports................................... S14 


\section{HPLC Charts}

$r a c-9 a$

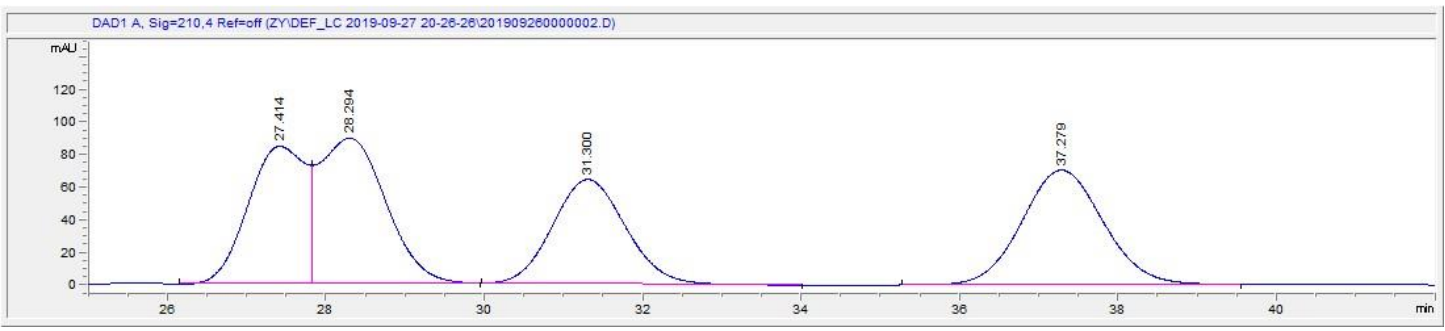

\begin{tabular}{|c|c|c|c|c|c|c|}
\hline$\#$ & Time & Area & Height & width & Area\% & Symmetry \\
\hline 1 & 27.414 & 4259.9 & 84.5 & 0.7583 & 23.045 & 1.273 \\
\hline 2 & 28.294 & 5187.5 & 89.3 & 0.8739 & 28.063 & 0.758 \\
\hline 3 & 31.3 & 4066.7 & 63.9 & 0.9859 & 22.000 & 0.902 \\
\hline 4 & 37.279 & 4970.9 & 70 & 1.1022 & 26.892 & 0.916 \\
\hline
\end{tabular}<smiles>C=CC(c1ccco1)[C@H](CO)CCCC[R16]C(C)C</smiles>

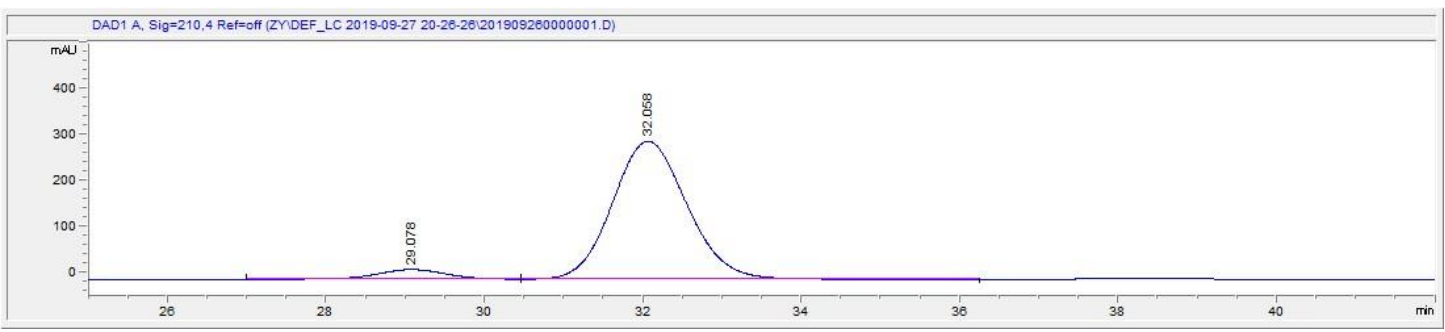

\begin{tabular}{|c|c|c|c|c|c|c|}
\hline$\#$ & Time & Area & Height & Width & Area\% & Symmetry \\
\hline 1 & 29.078 & 1174.8 & 20.4 & 0.8608 & 5.688 & 0.959 \\
\hline 2 & 32.058 & 19479.8 & 300 & 1.0075 & 94.312 & 0.878 \\
\hline
\end{tabular}




\section{Copies of ${ }^{1} \mathrm{H}$ and ${ }^{13} \mathrm{C}$ NMR spectra}

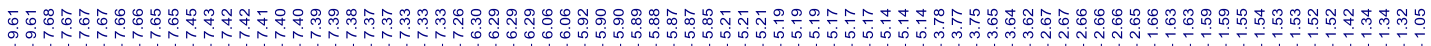

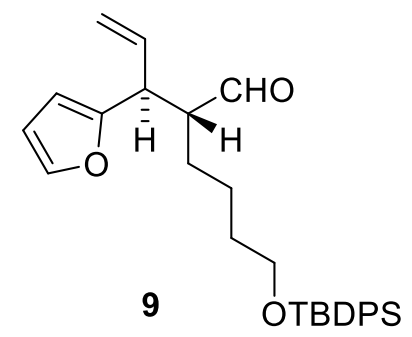

${ }^{1} \mathrm{H}$ NMR $\left(500 \mathrm{MHz}, \mathrm{CDCl}_{3}\right)$

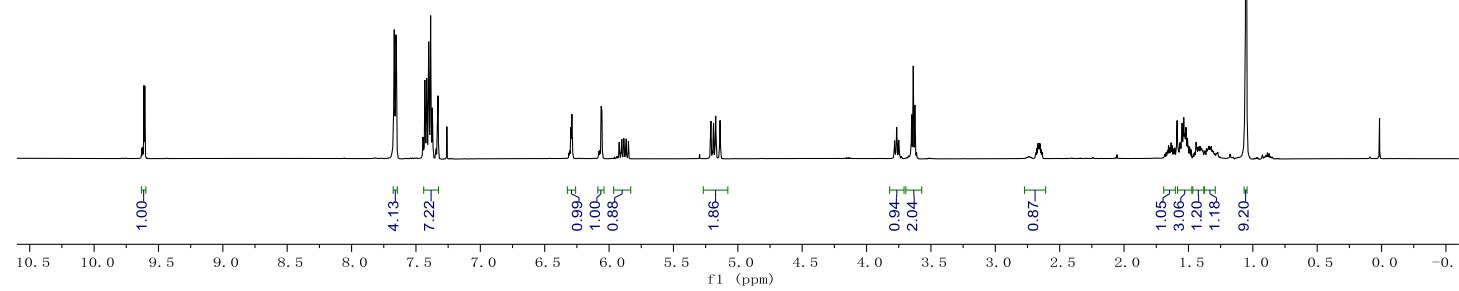

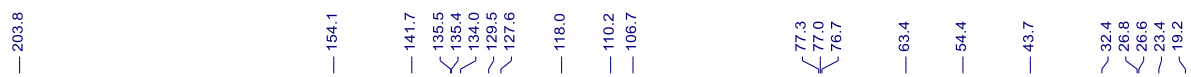
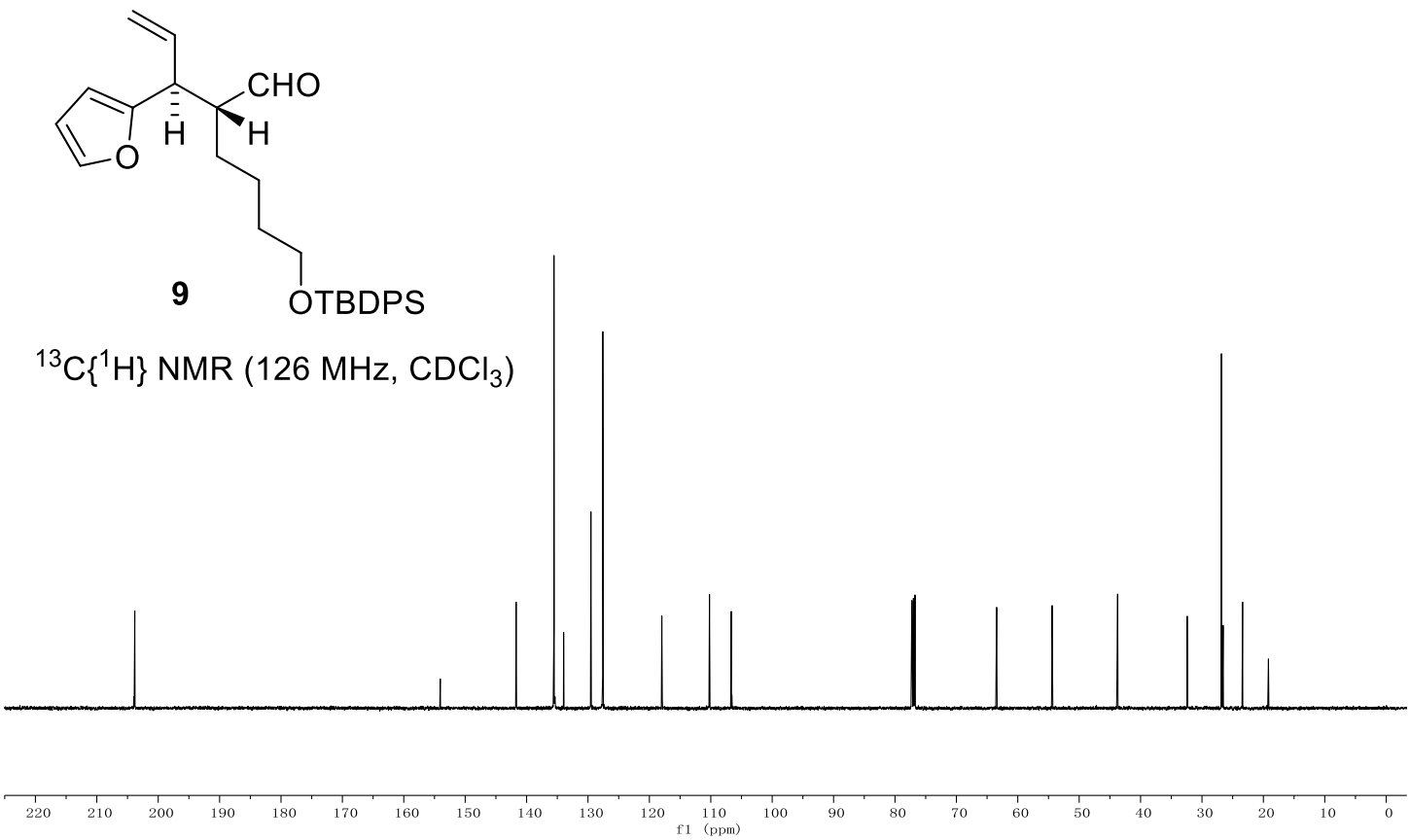


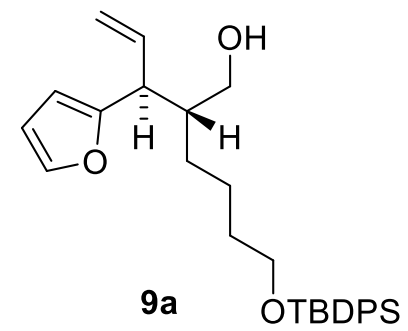

${ }^{1} \mathrm{H}$ NMR $\left(400 \mathrm{MHz}, \mathrm{CDCl}_{3}\right)$

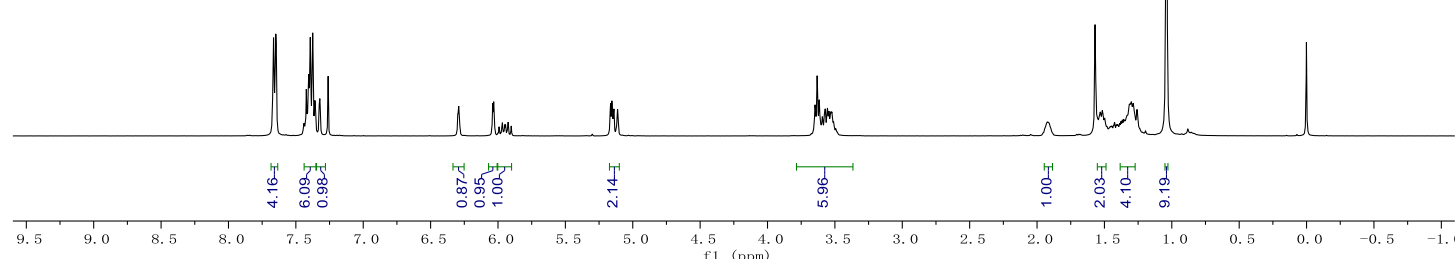

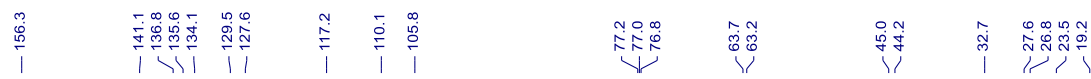<smiles>C=CC(c1ccco1)[C@H](CO)CCCC[R5]#[SH]</smiles>

${ }^{13} \mathrm{C}\left\{{ }^{1} \mathrm{H}\right\}$ NMR $\left(151 \mathrm{MHz}, \mathrm{CDCl}_{3}\right)$

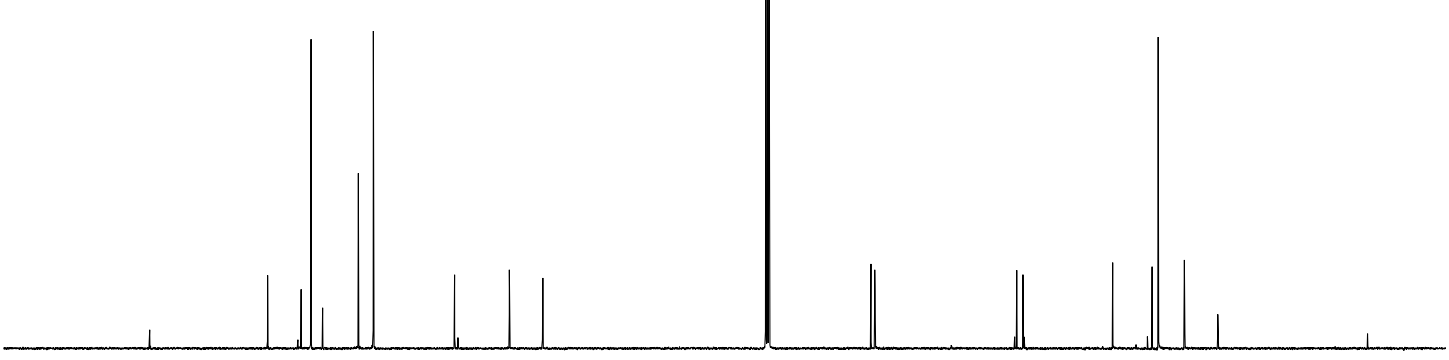

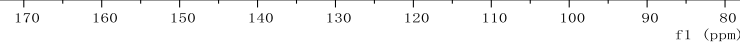




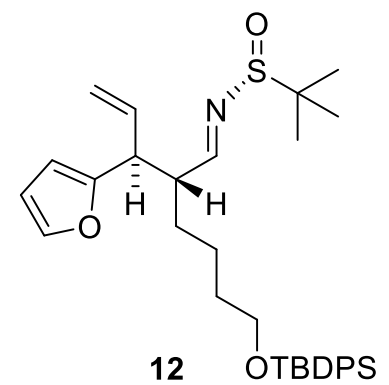

${ }^{1} \mathrm{H}$ NMR $\left(400 \mathrm{MHz}, \mathrm{CDCl}_{3}\right)$

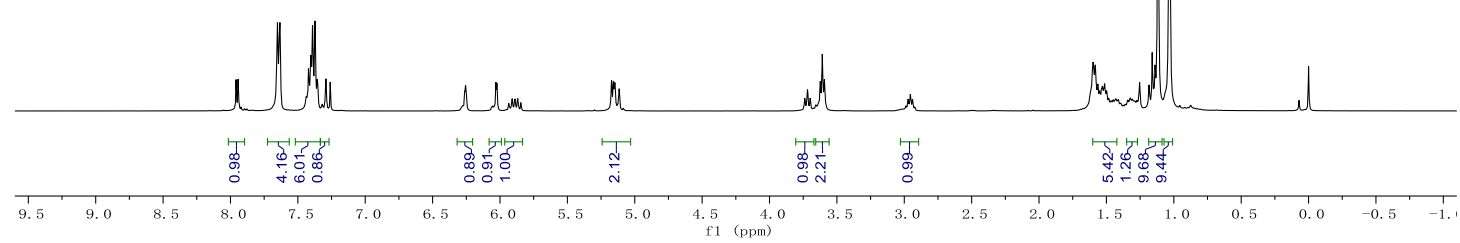

年

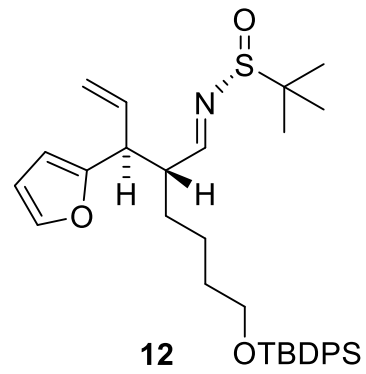

${ }^{13} \mathrm{C}\left\{{ }^{1} \mathrm{H}\right\}$ NMR $\left(151 \mathrm{MHz}, \mathrm{CDCl}_{3}\right)$

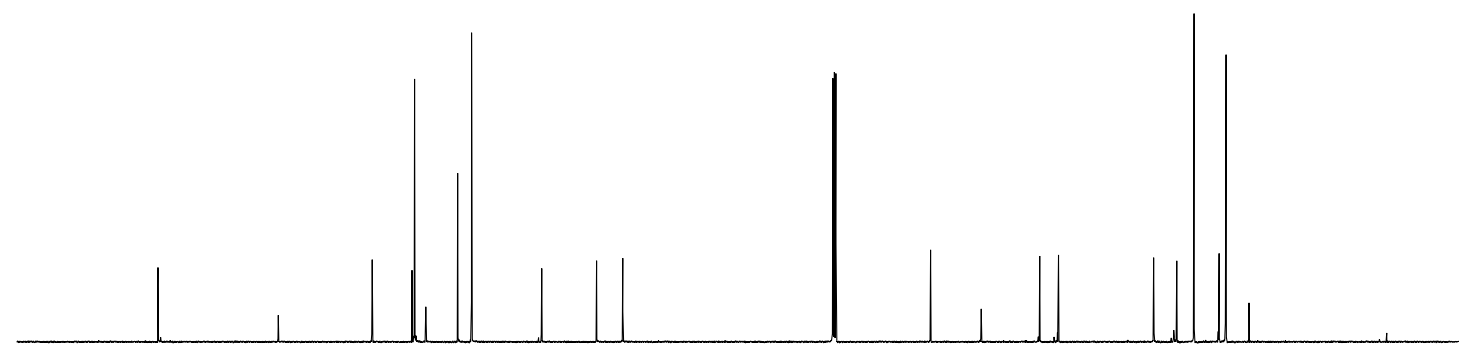

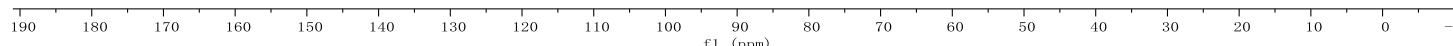




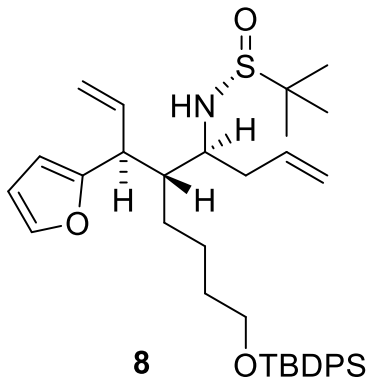

${ }^{1} \mathrm{H}$ NMR $\left(400 \mathrm{MHz}, \mathrm{CDCl}_{3}\right)$

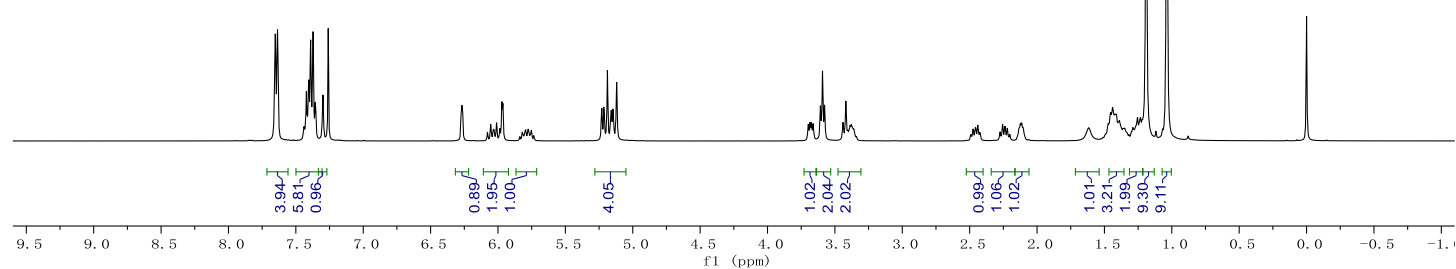

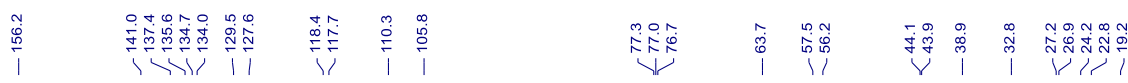

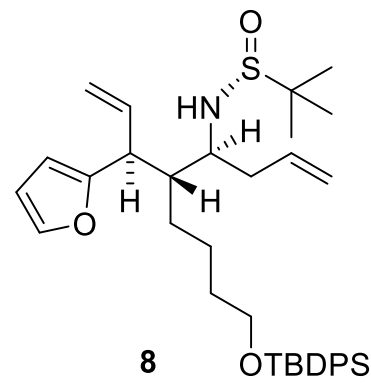

${ }^{13} \mathrm{C}\left\{{ }^{1} \mathrm{H}\right\} \operatorname{NMR}\left(126 \mathrm{MHz}, \mathrm{CDCl}_{3}\right)$
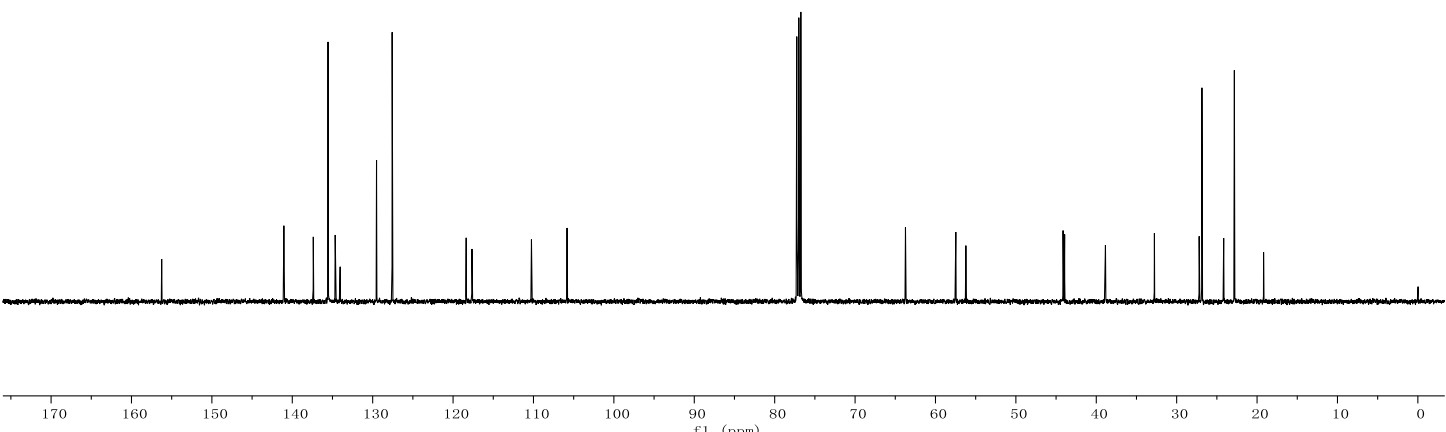


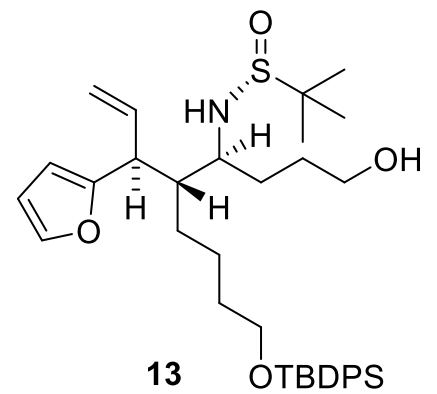

${ }^{1} \mathrm{H}$ NMR $\left(400 \mathrm{MHz}, \mathrm{CDCl}_{3}\right)$

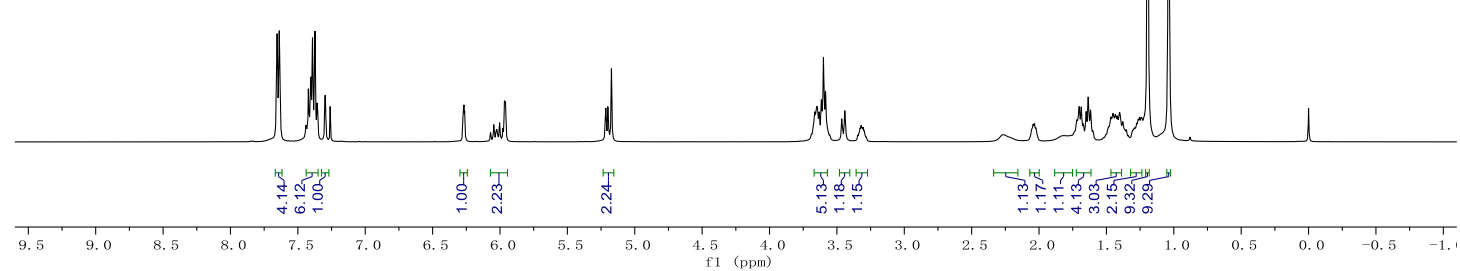

l

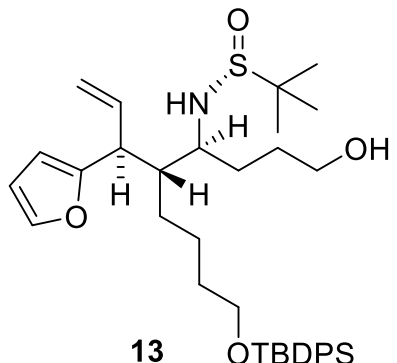

${ }^{13} \mathrm{C}\left\{{ }^{1} \mathrm{H}\right\}$ NMR $\left(151 \mathrm{MHz}, \mathrm{CDCl}_{3}\right)$
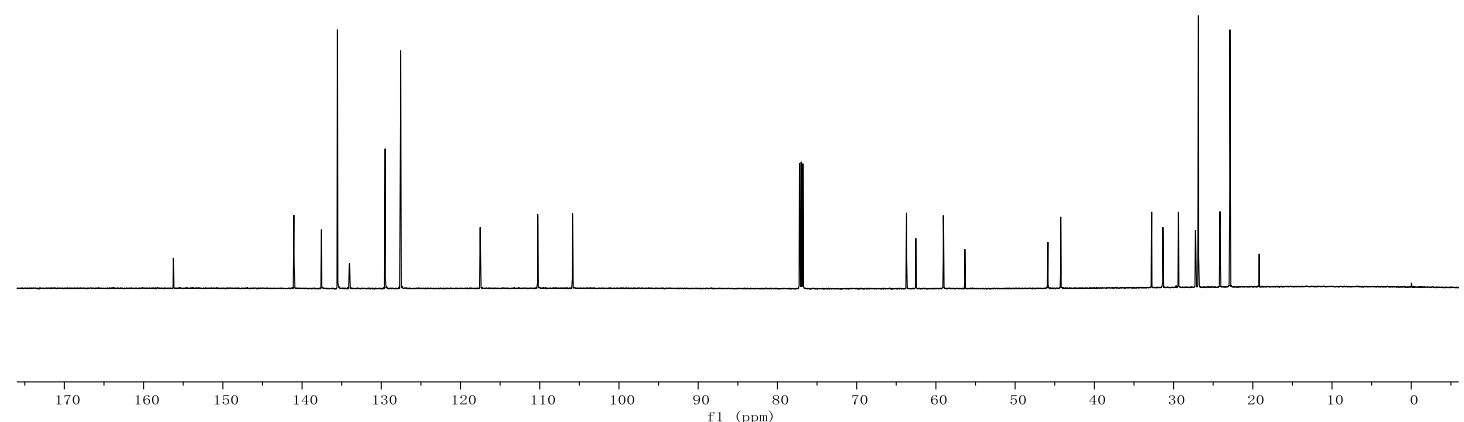


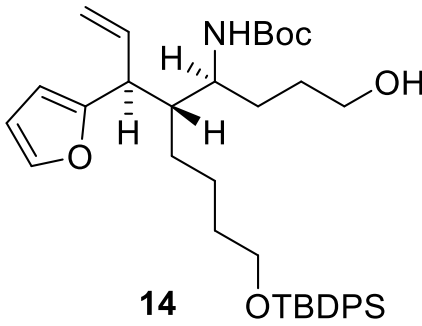

${ }^{1} \mathrm{H}$ NMR $\left(400 \mathrm{MHz}, \mathrm{CDCl}_{3}\right)$

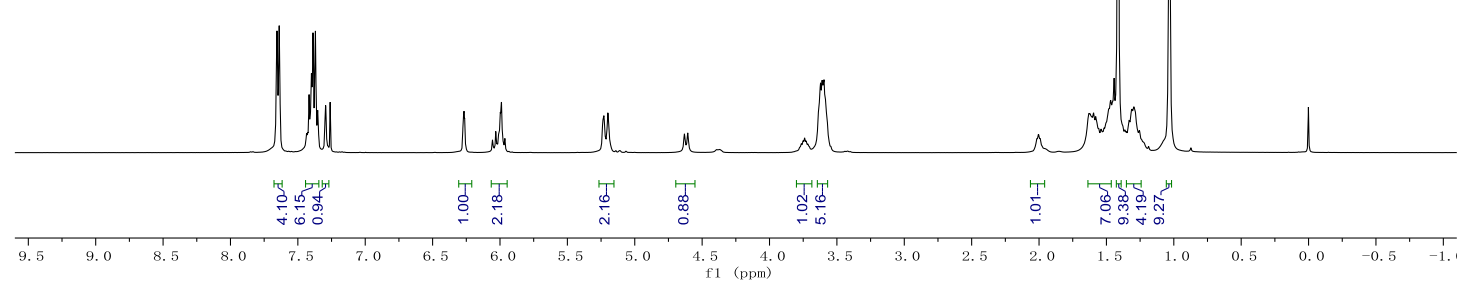

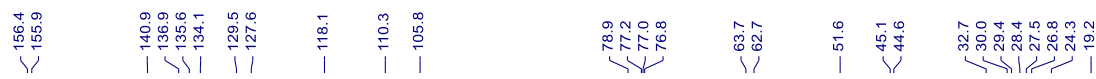<smiles>C=C[C@H](c1ccco1)[C@H](CCCCO[R5]#[SH])C(N)CCCO</smiles>

${ }^{13} \mathrm{C}\left\{{ }^{1} \mathrm{H}\right\}$ NMR $\left(151 \mathrm{MHz}, \mathrm{CDCl}_{3}\right)$
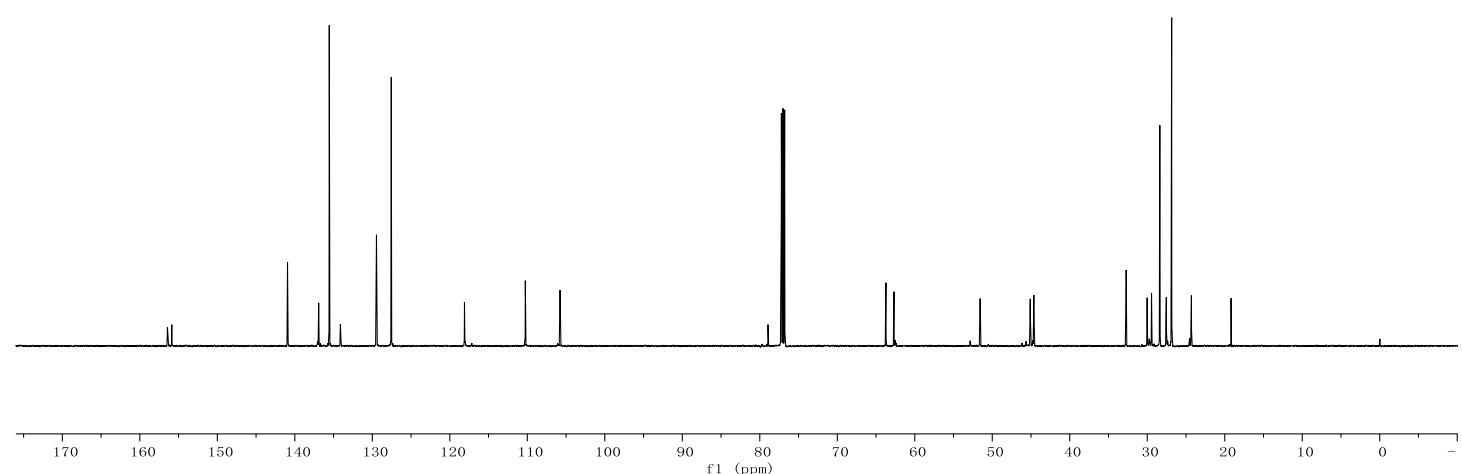


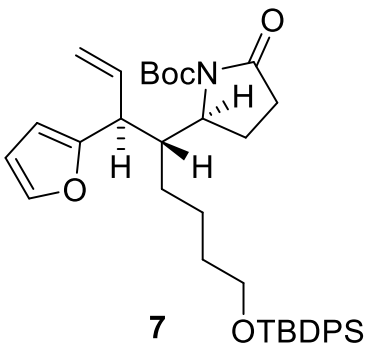

${ }^{1} \mathrm{H} \mathrm{NMR}\left(400 \mathrm{MHz}, \mathrm{CDCl}_{3}\right)$

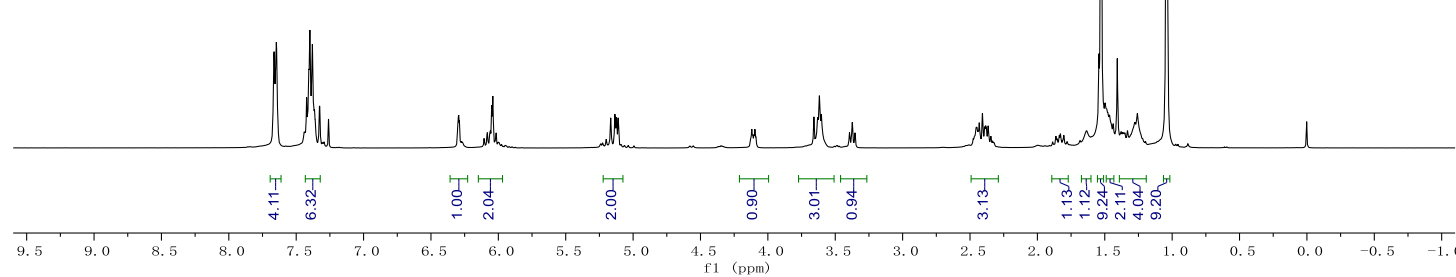

要

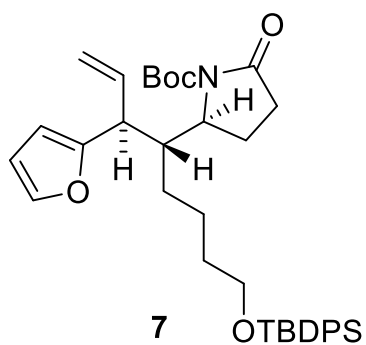

${ }^{13} \mathrm{C}\left\{{ }^{1} \mathrm{H}\right\}$ NMR $\left(101 \mathrm{MHz}, \mathrm{CDCl}_{3}\right)$
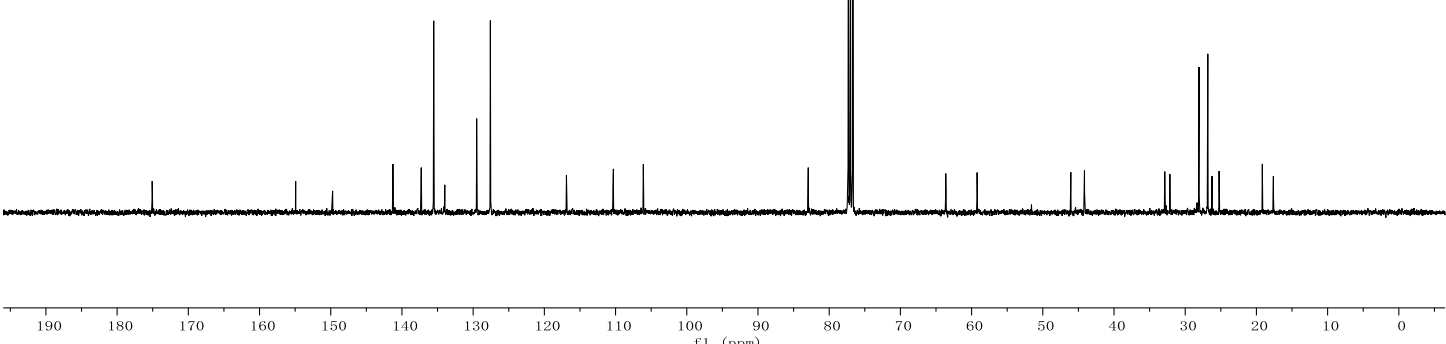


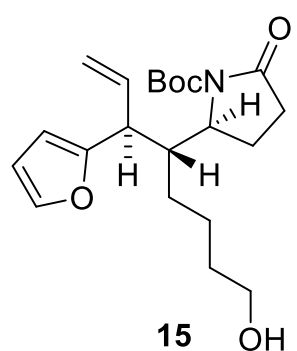

${ }^{1} \mathrm{H}$ NMR $\left(400 \mathrm{MHz}, \mathrm{CDCl}_{3}\right)$

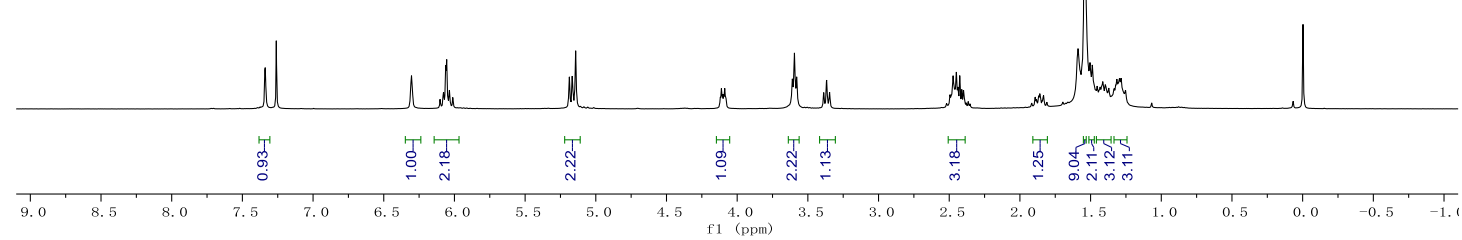

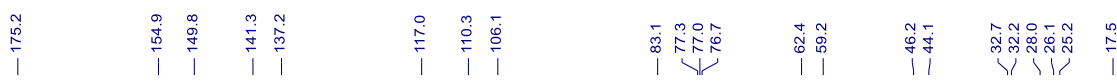

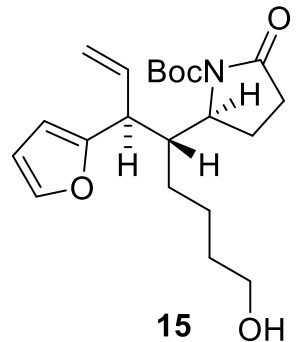

${ }^{13} \mathrm{C}\left\{{ }^{1} \mathrm{H}\right\}$ NMR $\left(101 \mathrm{MHz}, \mathrm{CDCl}_{3}\right)$

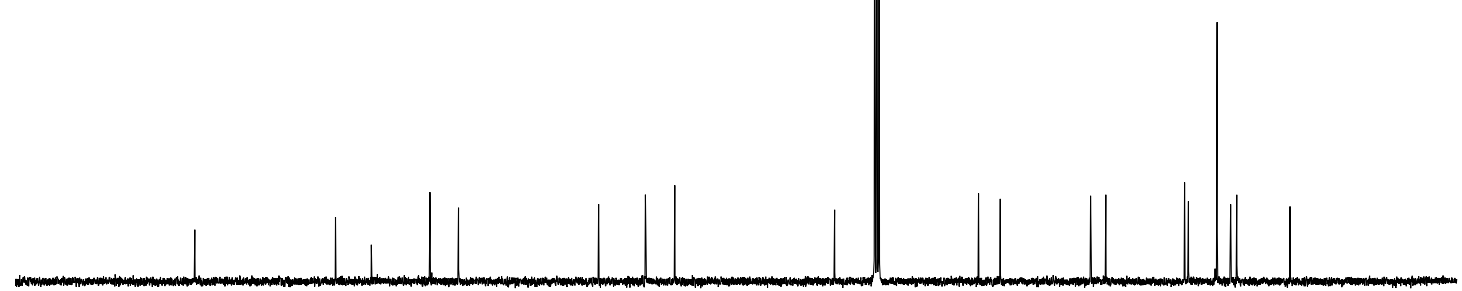

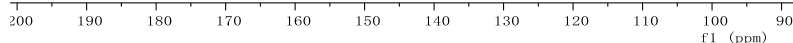


<smiles>C=C[C@H](c1ccco1)[C@H]1CCCCN2C(=O)CC[C@H]12</smiles>

6

${ }^{1} \mathrm{H}$ NMR $\left(600 \mathrm{MHz}, \mathrm{CDCl}_{3}\right)$

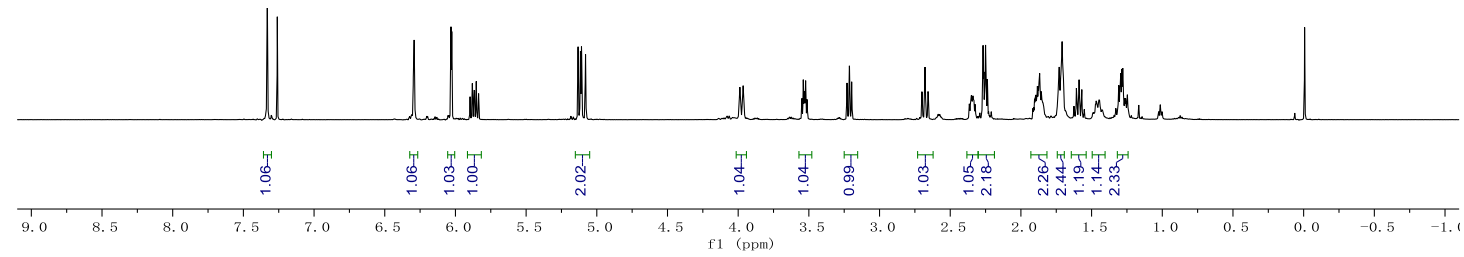

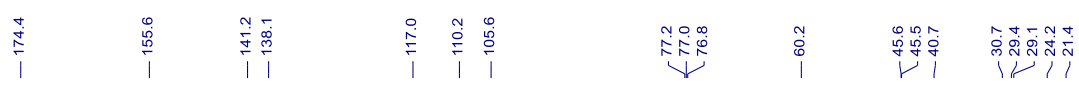

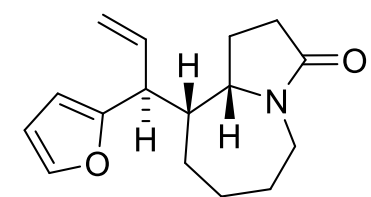

6

${ }^{13} \mathrm{C}\left\{{ }^{1} \mathrm{H}\right\} \operatorname{NMR}\left(151 \mathrm{MHz}, \mathrm{CDCl}_{3}\right)$

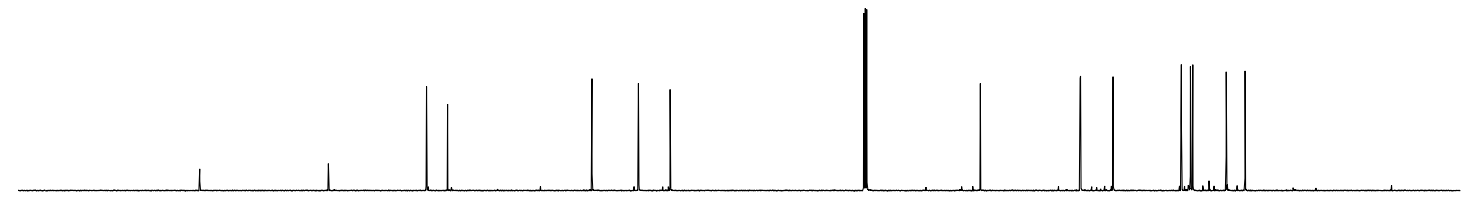

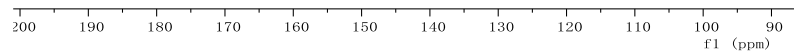




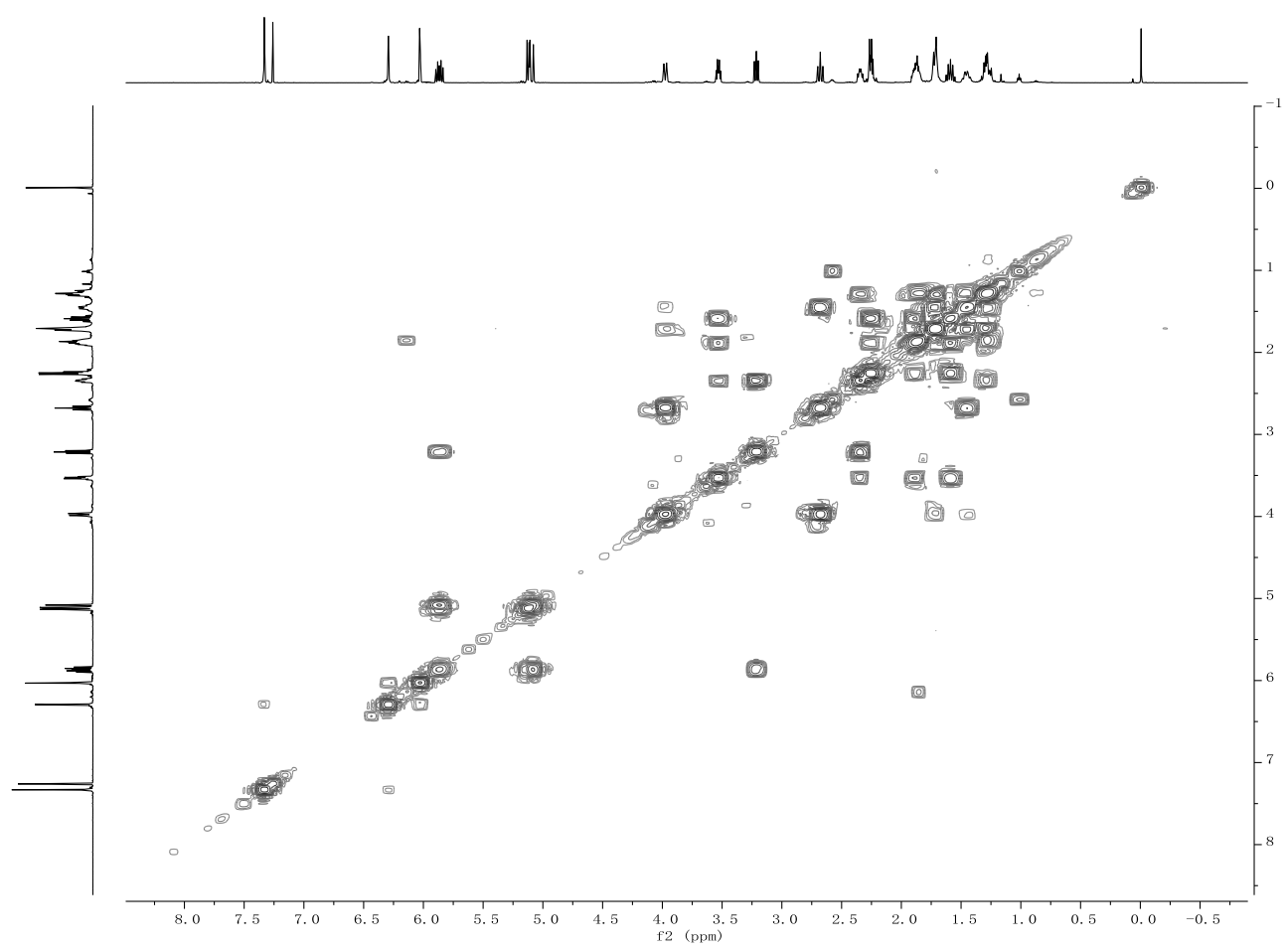

Figure S1. ${ }^{1} \mathrm{H}-{ }^{1} \mathrm{H}$ COSY spectrum of compound $6\left(600 \mathrm{MHz}, \mathrm{CDCl}_{3}\right)$.

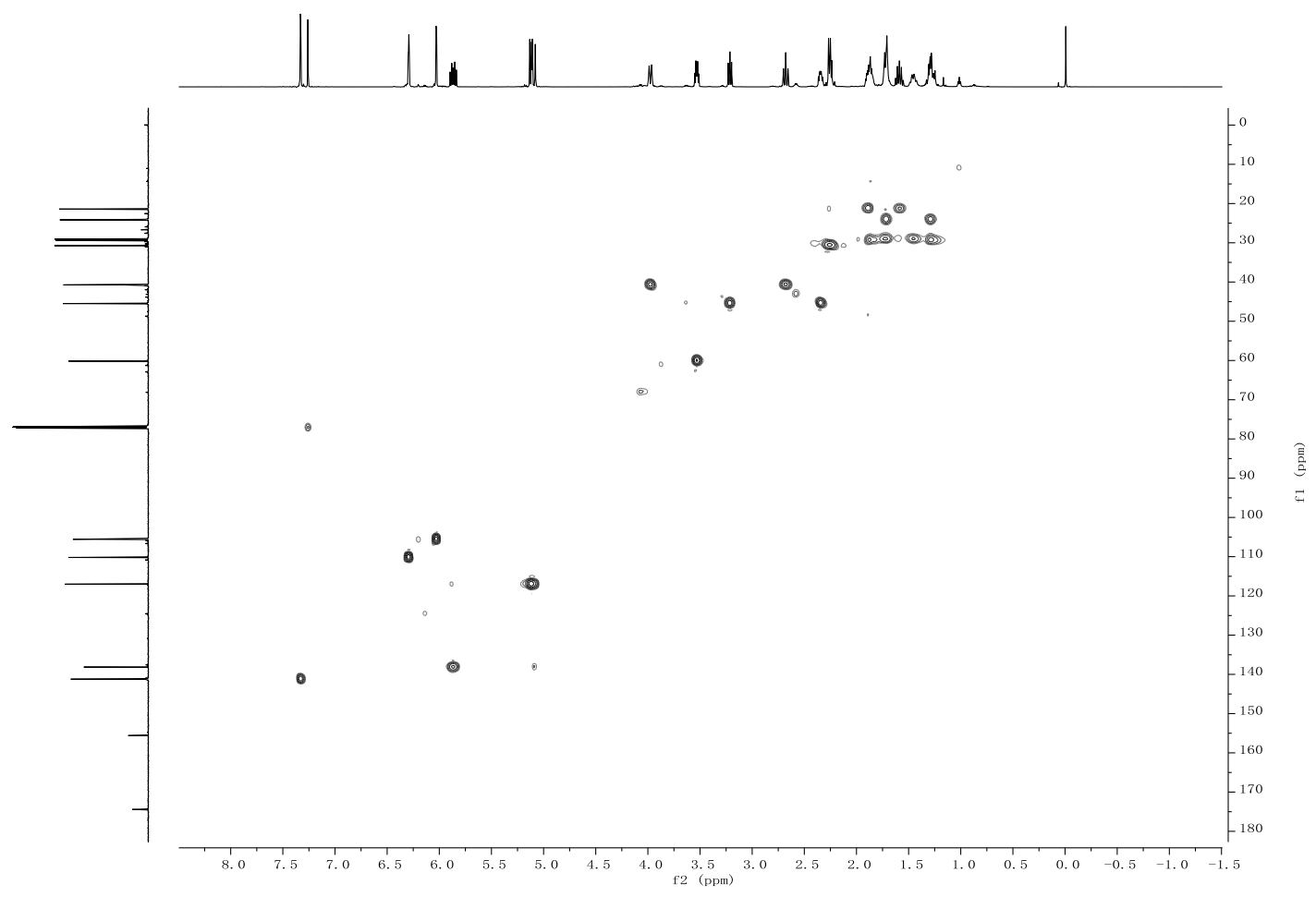

Figure S2. HSQC spectrum of compound $6\left(600 \mathrm{MHz}, 151 \mathrm{MHz}, \mathrm{CDCl}_{3}\right)$. 


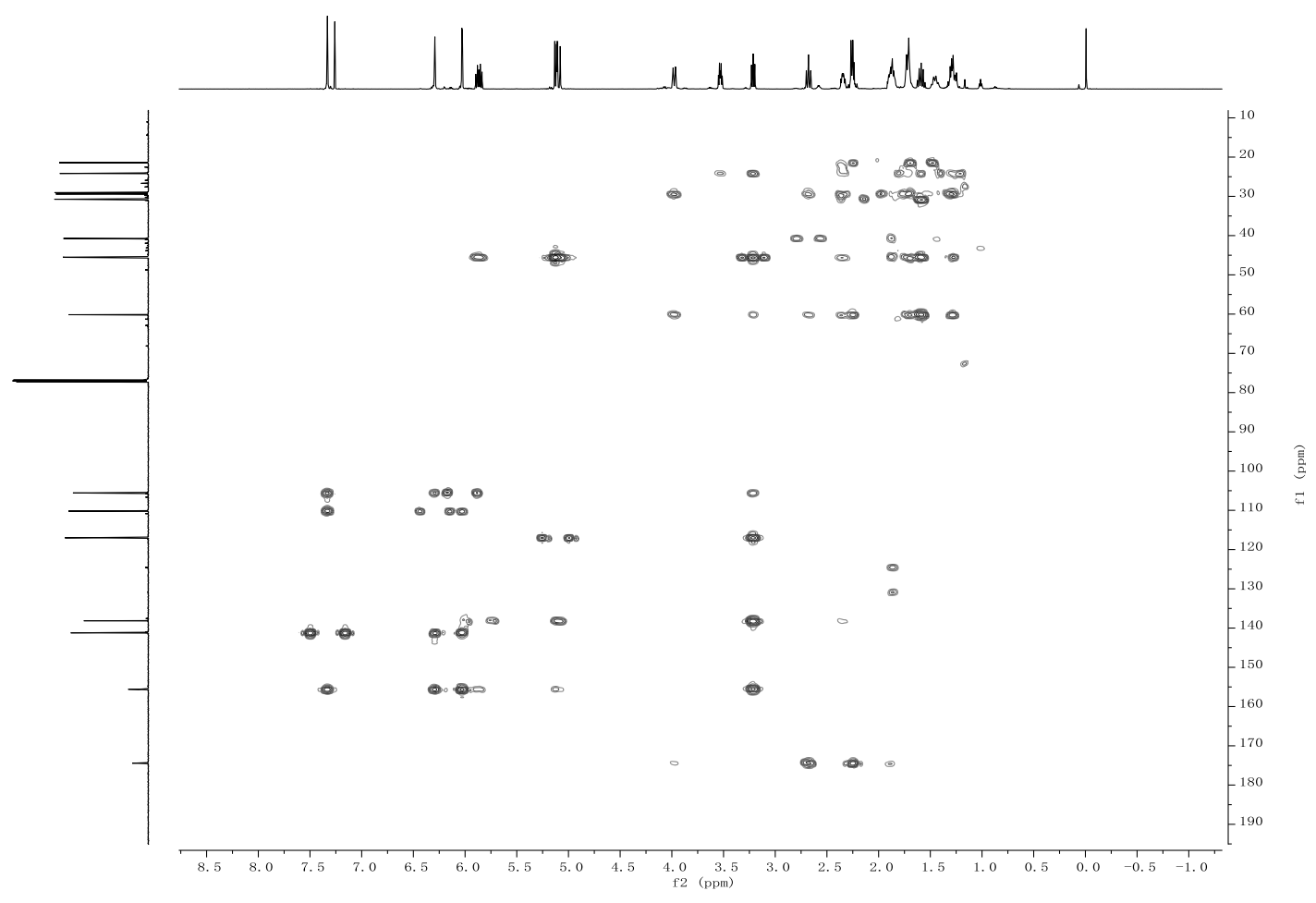

Figure S3. HMBC spectrum of compound $6\left(600 \mathrm{MHz}, 151 \mathrm{MHz}, \mathrm{CDCl}_{3}\right)$.

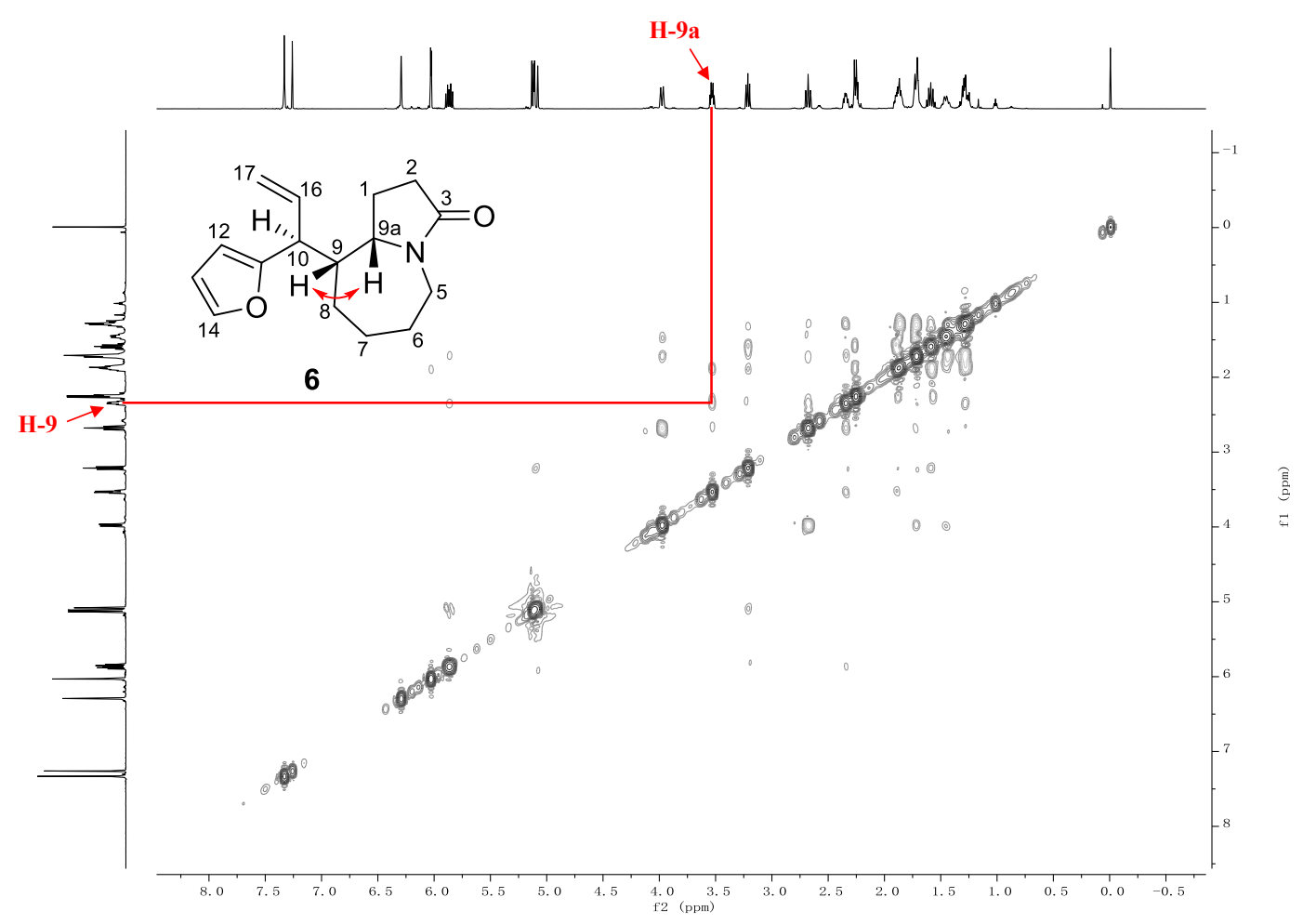

Figure S4. ROESY spectrum of compound $6\left(600 \mathrm{MHz}, \mathrm{CDCl}_{3}\right)$. 


\section{Parts of the HRMS analysis reports}

Formula Predictor Report - ahd04014.lcd

Data File: E:IDATAI202011210lahd04014.Icd

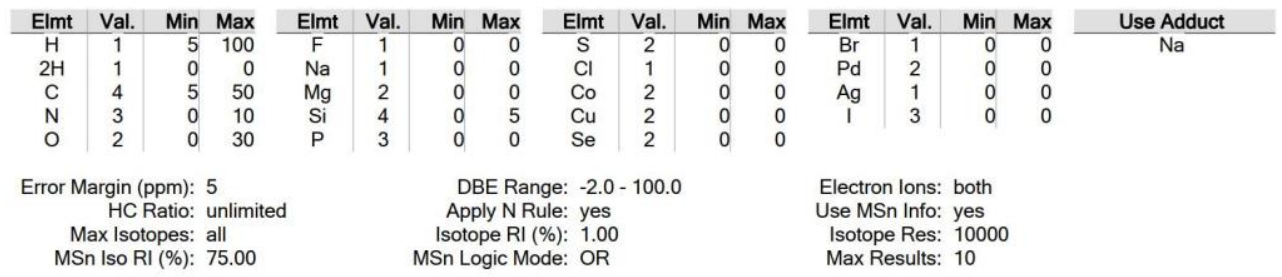

Event\#: $1 \mathrm{MS}\left(\mathrm{E}^{+}\right)$Ret. Time : 0.307 -> 0.413 Scan\# : 47 -> 63

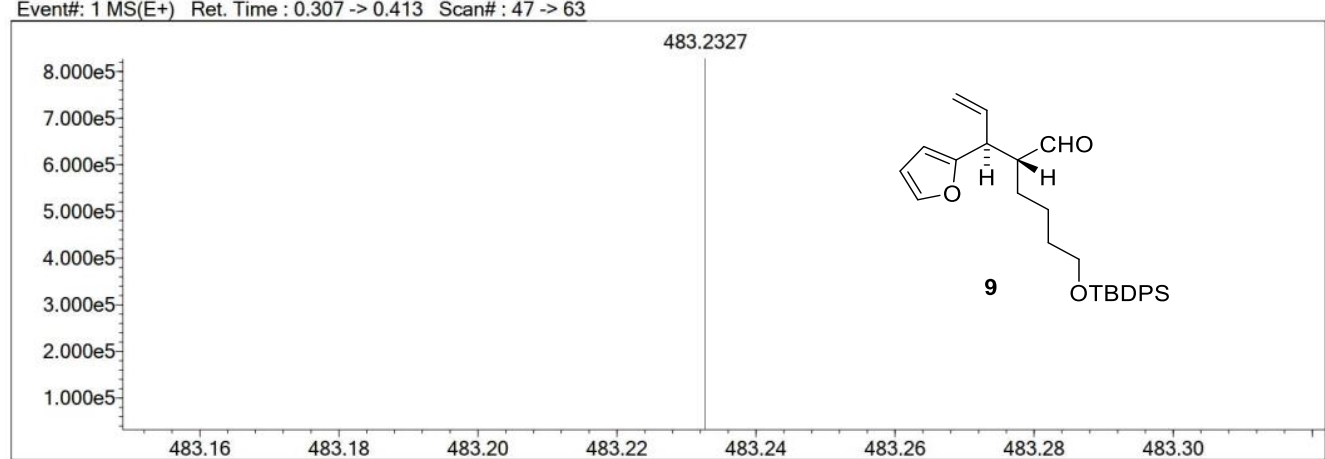

Measured region for $483.2327 \mathrm{~m} / \mathrm{z}$

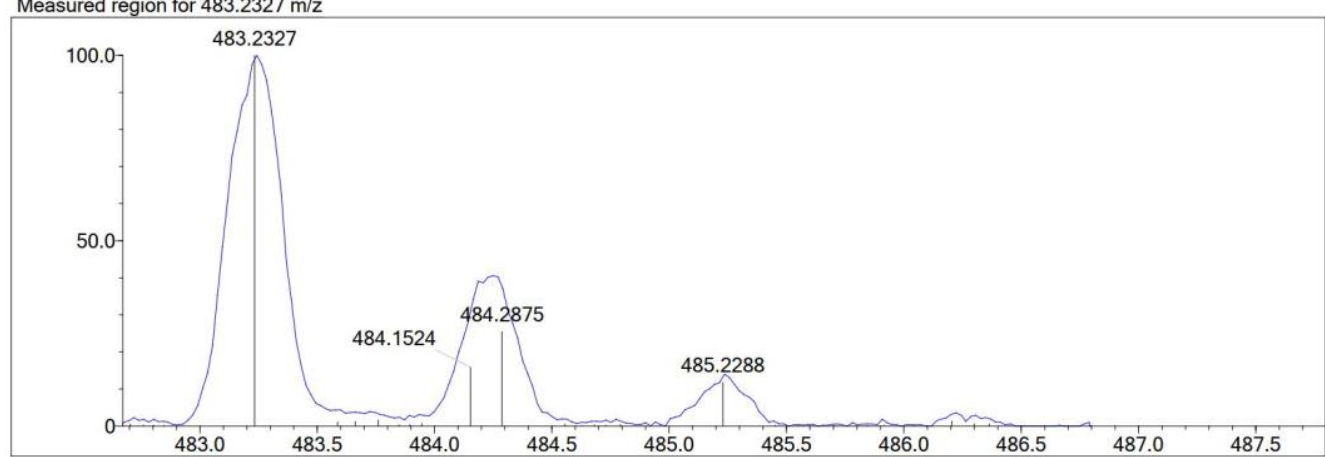

$\mathrm{C} 29 \mathrm{H} 36 \mathrm{O} 3 \mathrm{Si}[\mathrm{M}+\mathrm{Na}]+$ : Predicted region for $483.2326 \mathrm{~m} / \mathrm{z}$

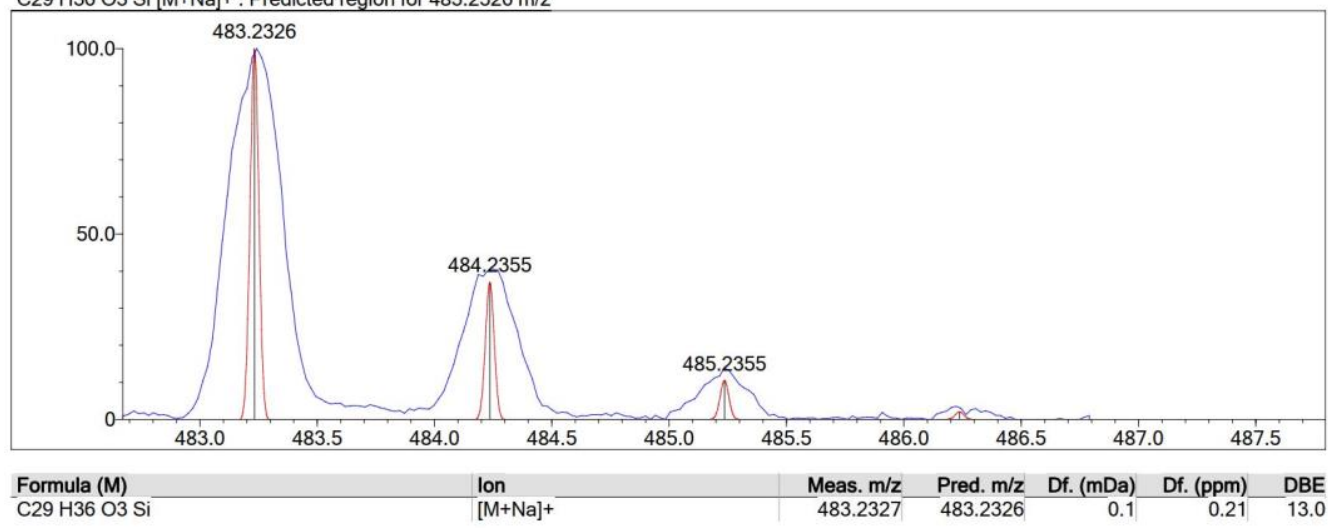


Data File: E:IDATAI202011222lahd04022.Icd

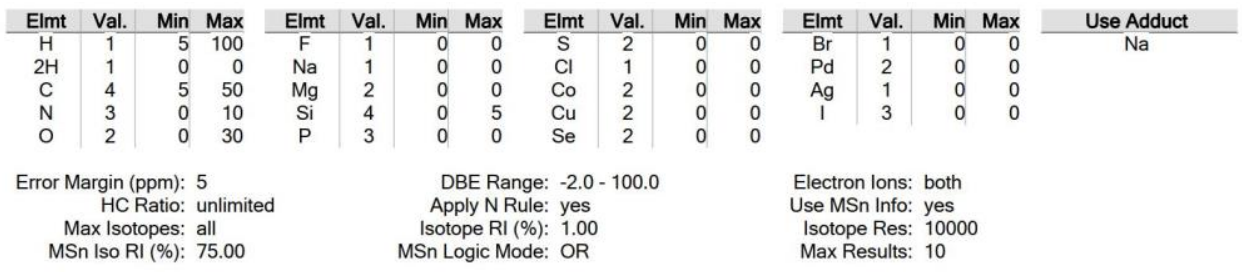

Event\#: $1 \mathrm{MS}(\mathrm{E}+)$ Ret. Time : $0.347 \rightarrow 0.733$ Scan\# : $53 \rightarrow 111$

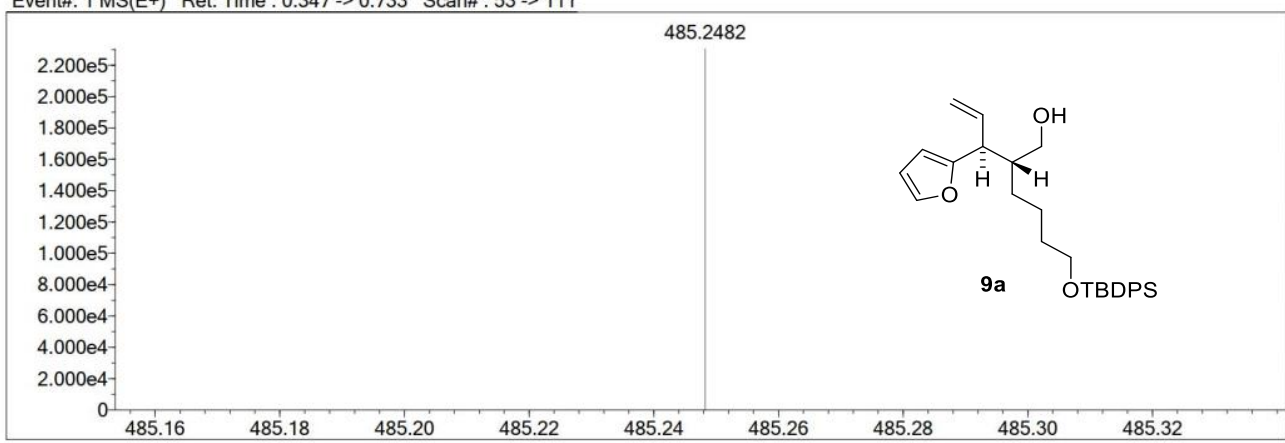

Measured region for $485.2482 \mathrm{~m} / \mathrm{z}$

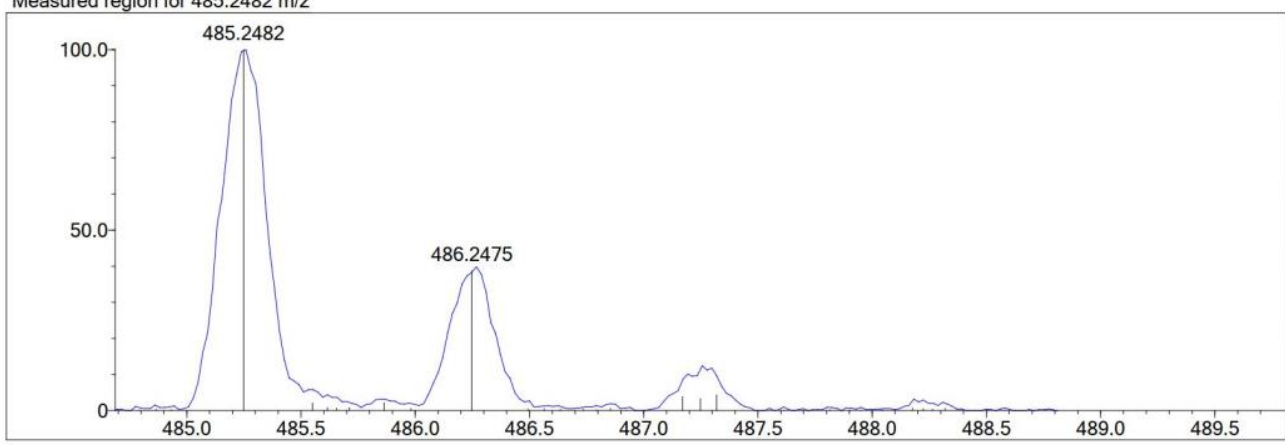

$\mathrm{C} 29 \mathrm{H} 38 \mathrm{O} 3 \mathrm{Si}[\mathrm{M}+\mathrm{Na}]+$ : Predicted region for $485.2482 \mathrm{~m} / \mathrm{z}$

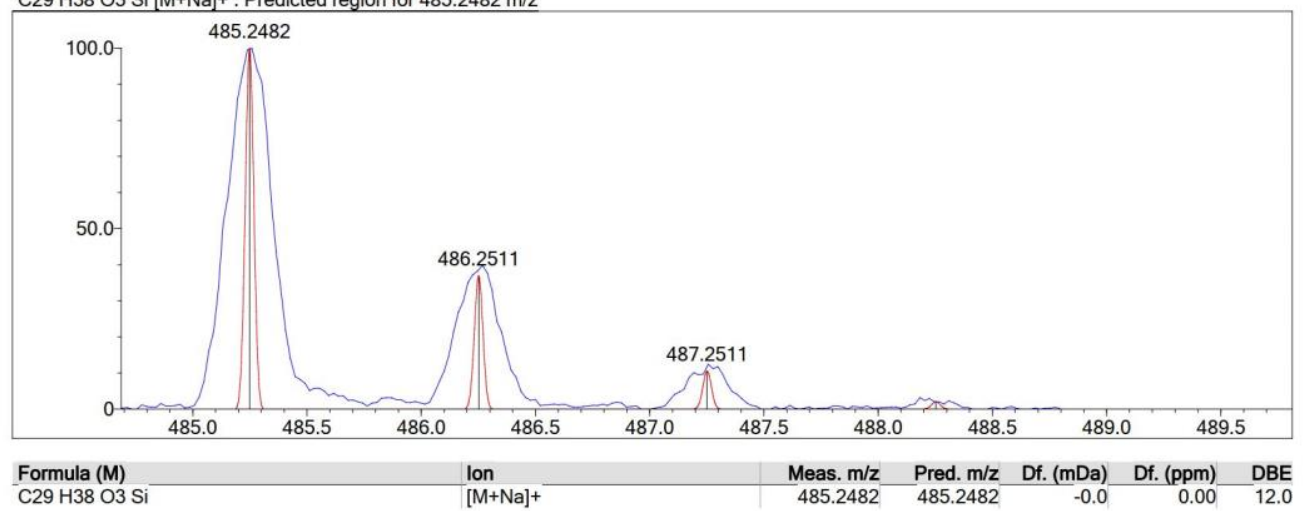


Data File: E:IDATAI202011214lAHD04018.Icd

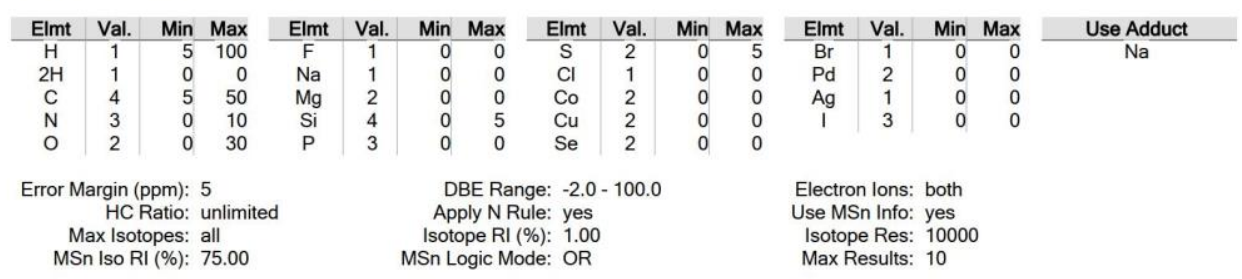

Event\#: $1 \mathrm{MS}\left(\mathrm{E}^{+}\right)$Ret. Time : 0.400 Scan\# : 61

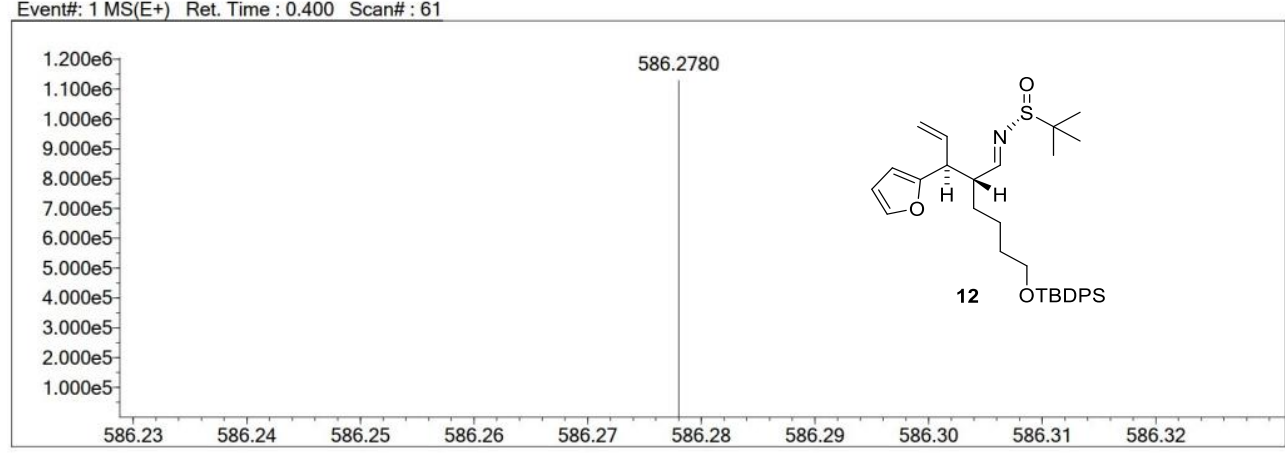

Measured region for $586.2780 \mathrm{~m} / \mathrm{z}$

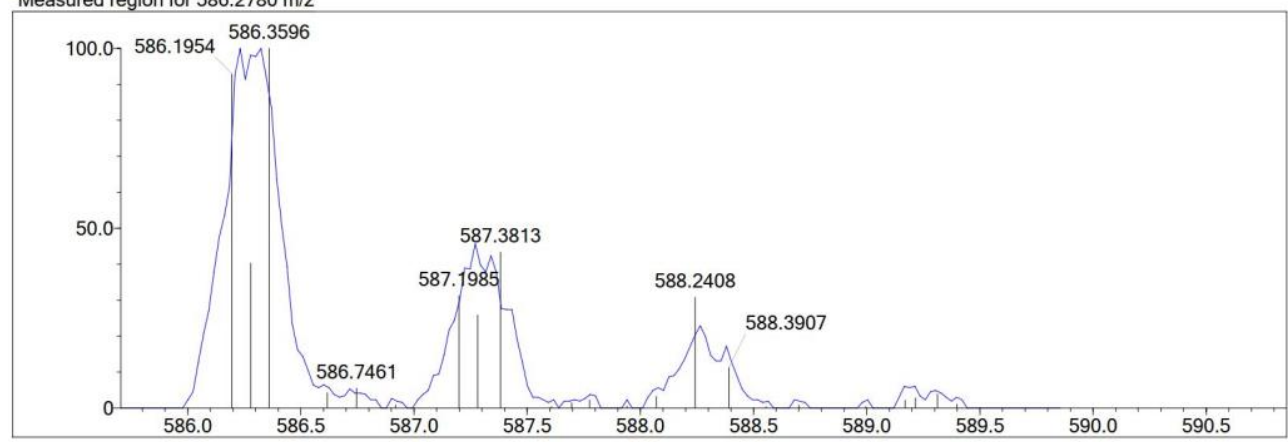

C33 H45 N O3 Si S [M+Na]+ : Predicted region for $586.2782 \mathrm{~m} / \mathrm{z}$

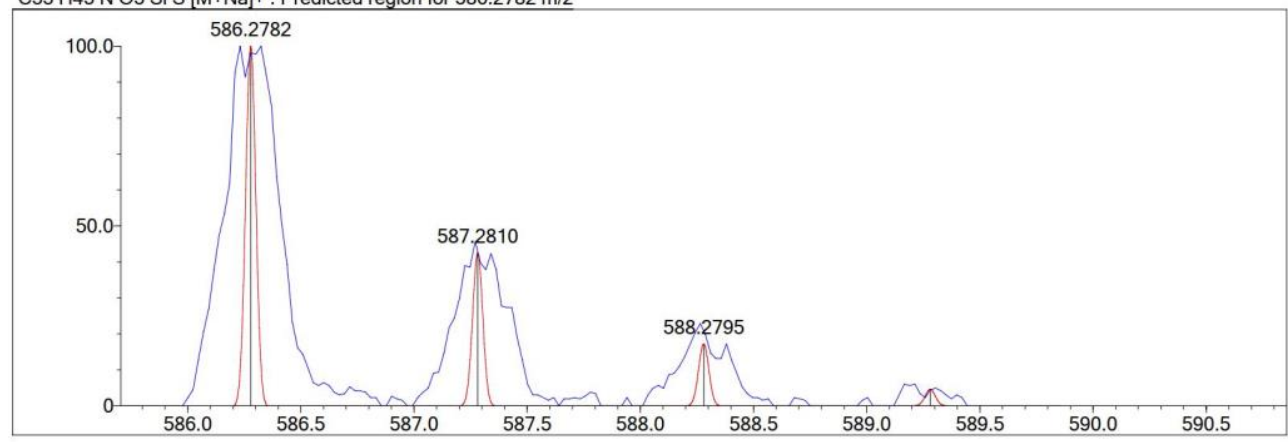

Formula (M)

$586.0 \quad 586.5 \quad 587.0$

on

$\begin{array}{lllll}\text { Meas. } \mathrm{m} / \mathrm{z} & \text { Pred. } \mathrm{m} / \mathrm{z} & \text { Df. }(\mathrm{mDa}) & \text { Df. (ppm) } & \text { DBE }\end{array}$

C33 H45 N O3 Si S

$[\mathrm{M}+\mathrm{Na}]+$

586.2780 Pred. $\mathrm{m} / \mathrm{z}$

$\begin{array}{lrl}-0.2 & -0.34 & 13.0\end{array}$ 


\section{Qualitative Analysis Report}

\begin{tabular}{|c|c|c|c|}
\hline Data Filename & azybai7.d & Sample Name & azybai7 \\
\hline Sample Type & Sample & Position & P1-A4 \\
\hline Instrument Name & Instrument 1 & User Name & \\
\hline Acq Method & s.m & Acquired Time & $12 / 14 / 202011: 23: 44 \mathrm{AM}$ \\
\hline $\begin{array}{l}\text { IRM Calibration Status } \\
\text { Comment }\end{array}$ & Success & DA Method & Default.m \\
\hline Sample Group & & & \\
\hline $\begin{array}{l}\text { Acquisition SW } \\
\text { Version }\end{array}$ & $\begin{array}{l}\text { ies TOF/6500 series } \\
.05 .01(B 5125.2)\end{array}$ & & \\
\hline
\end{tabular}

User Spectra
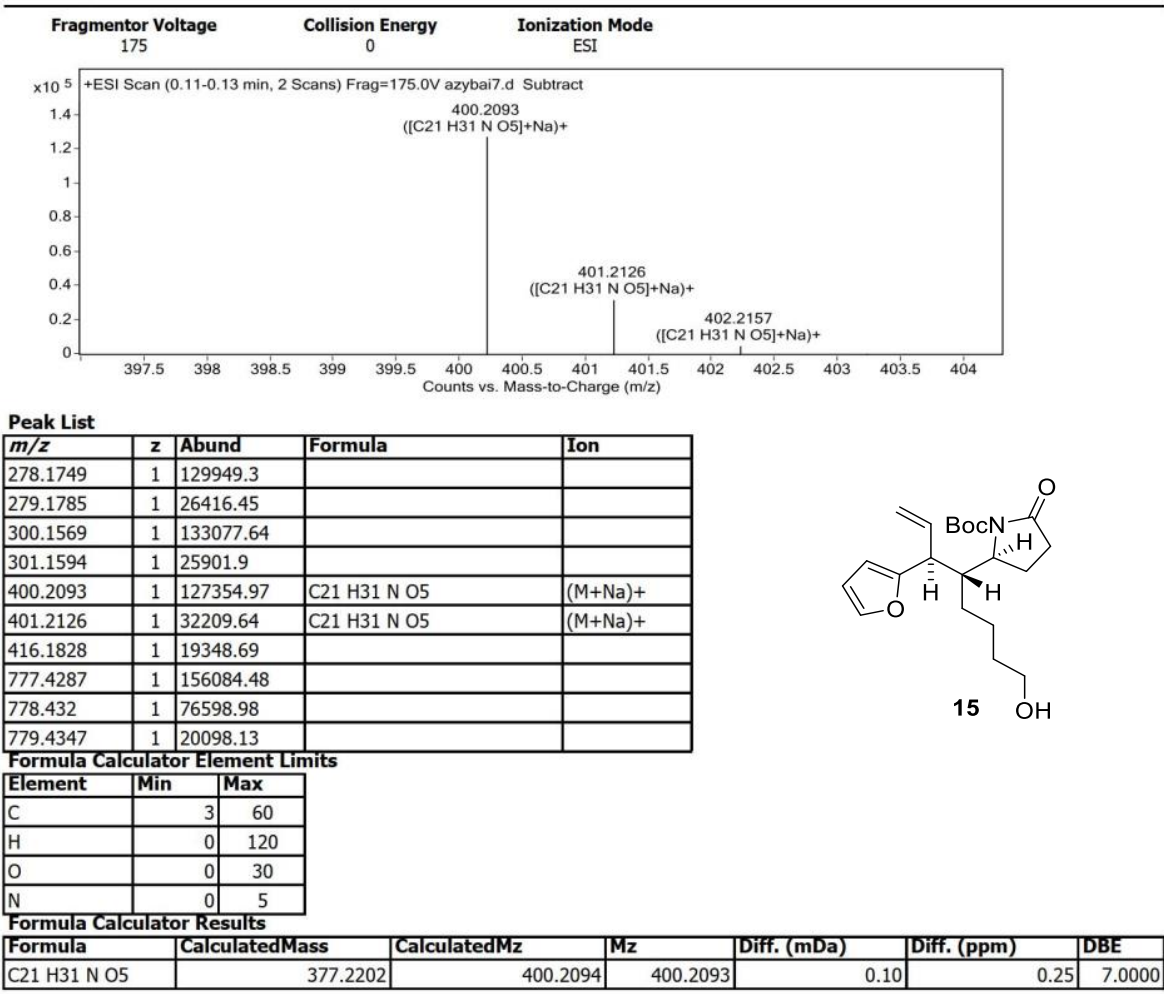

--- End Of Report -- 